\title{
O ENSINO DE SOCIOLOGIA E A PEDAGOGIA HISTÓRICO-CRÍTICA: UMA ANÁLISE DOS FUNDAMENTOS TEÓRICO-METODOLÓGICOS DAS PROPOSTAS ATUAIS
}

\author{
Davisson Charles Cangussu de Souza ${ }^{1}$
}

\begin{abstract}
RESUMO
$\mathrm{O}$ artigo tem o objetivo de contribuir para o debate sobre o ensino de Sociologia, explicitando os fundamentos teórico-metodológicos presentes nas principais propostas curriculares. Para tanto, faz uma análise dos documentos oficiais e de alguns livros didáticos da disciplina, apresentando uma crítica à abordagem predominante que parte dos conceitos de estranhamento e desnaturalização, e ao procedimento que reproduz a discussão acadêmica baseada na diversidade teórica de seus autores. Com base na Pedagogia Histórico-Crítica, busca problematizar as propostas existentes, apontando alguns pressupostos epistemológicos, sociológicos e pedagógicos que poderiam contribuir para superar algumas dificuldades e dilemas que vêm sendo apontadas pela bibliografia nas práticas de ensino da disciplina.

Palavras-chaves: Ensino de Sociologia. Ensino Médio. Pedagogia Histórico-Crítica. Propostas curriculares. Livros didáticos de Sociologia.
\end{abstract}

\section{TEACHING SOCIOLOGY AND CRITICAL-HISTORICAL PEDAGOGY: PRELIMINARY NOTES FOR THE CONSTRUCTION OF A DIDACTIC PROPOSAL}

\begin{abstract}
The article intends to contribute to the debate of Teaching Sociology, explaining the theoretical-methodological fundamentals of the major curricular proposals. For this, it does an analysis of official documents and some textbooks of the discipline, showing critics of the prevailing approach to concepts of strangeness and denaturalization, as well as the procedure that reproduce the academic discussion treating the theoretical diversity of the authors. Inspired by the historical-critical Pedagogy, it intends to discuss the existing proposals, pointing some epistemological sociological and educational assumptions, that could resolve some difficulties and dilemmas that the bibliography has debated about the teaching practices of the discipline.

Keywords: Teaching of sociology. High School. Critical-Historical Pedagogy. Curricular proposals. Textbooks of Sociology.
\end{abstract}

\section{Introdução $^{2}$}

O objetivo deste artigo é problematizar algumas questões teórico-metodológicas presentes no atual debate sobre o ensino de Sociologia. Para tanto, o texto parte de alguns pressupostos da Pedagogia Histórico-Crítica (PHC), teoria desenvolvida pelo filósofo da educação brasileira Dermeval Saviani no início dos anos 1980. A PHC possui uma correspondência epistemológica com o materialismo histórico-dialético, o que repercute em sua noção de sociedade, bem como da relação desta com a educação e do processo pedagógico. Com base nesse ponto de partida, o artigo pretende fazer uma análise das 
propostas didáticas atuais e problematizar algumas questões que vem desafiando as práticas de ensino da Sociologia. ${ }^{3}$

$\mathrm{O}$ atual debate sobre o ensino de Sociologia vem carecendo de discussões que explicitem a abordagem teórico-metodológica dos autores dos documentos oficiais e dos principais livros didáticos. Embora se apresentem freqüentemente como "ecléticas" em sua forma de exposição ${ }^{4}$, as atuais propostas curriculares estão orientadas por interpretações específicas acerca dos temas, das teorias e dos conceitos sociológicos. O procedimento metodológico fundado na noção de que um dos pressupostos da Sociologia é a sua "diversidade teórica" tende a ocultar os pilares epistemológicos presentes nas diferentes propostas. Ademais, contribui para difundir a noção de que é possível a neutralidade axiológica (e político-ideológica) da disciplina. Essa idéia é defendida tanto pelo positivismo como pelo individualismo metodológico o qual, apesar de admitir a impossibilidade de que a ciência (e o currículo) sejam neutros na escolha dos objetos (e dos conteúdos), sustenta esta possibilidade no tratamento teórico-metodológico nos procedimentos de pesquisa (e de ensino). Procuraremos sustentar que o ponto de partida na diversidade de abordagens apresenta uma desvantagem por conta da necessidade de estar sustentado em um debate muito amplo sobre as teorias e os conceitos de autores cuja complexidade torna seu tratamento inadequado para a Sociologia no Ensino Médio. O presente texto busca problematizar esse procedimento e suas consequiências sobre as práticas de ensino da disciplina. $^{5}$

Tal como reconhece o próprio Saviani, tanto a didática como o currículo na PHC estão em processo de construção. Embora alguns trabalhos tenham avançado nesse propósito, é possível afirmar que esses avanços ainda não alcançaram a disciplina Sociologia. Esperemos, com este texto, contribuir para preencher essa lacuna.

$\mathrm{O}$ texto está dividido em três partes. Na primeira, serão feitas algumas considerações sobre o ensino de Sociologia, buscando localizar os fundamentos teóricometodológicos presentes nos principais documentos oficiais e nos materiais didáticos da disciplina. Em seguida, serão feias algumas apreciações sobre a PHC. Por fim, serão apresentados alguns argumentos sobre como a PHC pode contribuir para o ensino de Sociologia ao buscar superar algumas dificuldades presentes nas práticas de ensino e nas propostas curriculares atuais.

\section{1) Pressupostos teórico-metodológicos das propostas curriculares atuais}

Não é novidade nas discussões pedagógicas que a abordagem presente nas propostas curriculares e nos manuais seja devedora, implícita ou explicitamente, da orientação teórica e epistemológica presente em sua formulação. ${ }^{6}$ Esta orientação pode ser evidenciada não só na escolha dos conteúdos e na forma de abordá-los, mas também na metodologia, na didática e nas práticas de ensino propostas. A partir desses pressupostos, sempre é possível identificar e problematizar as concepções de ensino-aprendizagem, de inteligência e de conhecimento, de linguagem, de ser humano, de natureza e de sociedade presentes nos livros didáticos e nos documentos oficiais. Por um lado, é importante ler as propostas curriculares a partir de sua matriz teórica e identificar as implicações políticoideológicas de suas escolhas. Por outro, o conhecimento deste debate é de suma importância para que os professores (atuais e futuros) possam fundamentar suas opções pedagógicas. Estes argumentos estão baseados no pressuposto da indissociabilidade entre teoria e prática, e entre ciência e política, que se contrapõe à concepção liberal de neutralidade da educação. Para o objeto aqui analisado - o ensino de Sociologia-, a implicação mais direta deste fundamento está na noção de "diversidade teórica", que 
pressupõe o tratamento equivalente às diferentes matrizes da disciplina sem tomada de posição de nenhuma delas. Uma das principais consequiências desta concepção do processo de ensino está na idéia de que a explicitação da filiação teórica (pelas propostas curriculares, pelos livros e pelos professores) seria uma postura dogmática e panfletária, pois limitaria os alunos ao contato com apenas uma abordagem, impossibilitando-os do acesso ao conhecimento de um leque de "opções" que os conduzissem a uma "livre escolha". Em outras palavras, a presença declarada de objetivos teóricos (e políticos) nas aulas (como se sua ausência fosse possível) seria algo doutrinário, adestrador e "ideológico", ideologia aqui entendida, de acordo com a visão positivista, como resultante do "descuido" metodológico com a necessária isenção de valores para o desenvolvimento do conhecimento científico. Este trabalho parte da noção de impossibilidade da neutralidade teórica e política no processo educacional e pedagógico, tanto por parte dos professores, como por parte das propostas curriculares oficiais e dos autores de livros didáticos. Ao contrário, observa-se a necessidade de explicitá-lo, assumindo-o como parte do processo pedagógico. Tal como sustenta Paulo Freire (1996),

Em nome do respeito que devo aos alunos não tenho porque me omitir, por que ocultar a minha opção política, assumindo uma neutralidade que não existe. Essa, a omissão do professor em nome do respeito ao aluno, talvez seja a melhor maneira de desrespeitá-lo. O meu papel, ao contrário, é o de quem testemunha o direito de comparar, de escolher, de romper, de decidir e estimular a assunção deste direito por parte dos educandos. (FREIRE, 1996, p. 71).

Feitos estes esclarecimentos metodológicos iniciais, será realizado um exercício de análise dos seguintes documentos e livros de Sociologia: i) os Parâmetros Curriculares Nacionais (PCN) (BRASIL, 1998); ii) as Orientações Curriculares Nacionais (OCN) (BRASIL, 2006) ${ }^{7}$, iii) a Proposta Curricular do Estado de São Paulo para a disciplina de Sociologia (SEE/SP, 2009b), elaborada pela Secretaria Estadual de Educação (SEE/SP); iv) os Cadernos de Sociologia (Manual do Aluno e Manual do Professor) (SEE/SP, 2009a) criados a partir deste último documento; v) o livro Tempos modernos, tempos de Sociologia (BOMENY, MEDEIROS, 2011); e vi) o livro Sociologia para o ensino médio (TOMAZI, 2011), os dois últimos, os únicos indicados pelo Programa Nacional do Livro Didático (PNLD) na última avaliação feita pelo Ministério da Educação (MEC). ${ }^{8}$

De modo geral, pode-se afirmar que a matriz epistemológica weberiana vem predominando na construção dos currículos de Sociologia no Brasil. Os PCN (BRASIL, 1998) deixam explícita esta filiação teórica em várias passagens. Primeiramente, ao defender o conceito de relação social como "unidade elementar" da disciplina, apresentam os conceitos de "rede de relações sociais" e "interação social" com referência explícita à sociologia weberiana. Propõem, ainda, que se siga o modelo de estratificação social de Weber, baseando-se em sua abordagem dos conceitos de castas, estamentos e classes sociais. Por último, ao tratar do Estado, define-o como uma instância que "racionaliza a distribuição do poder legítimo dentro de uma nação", o que deixa novamente explícita sua filiação teórica weberiana. Esta opção fica clara não só por este repertório conceitual que o documento utiliza, mas também pela simplificação do pensamento de Marx e Durkheim, e pelo papel secundário atribuído a estes autores ao longo do texto. Por exemplo, ao tratar a categoria trabalho, indica a necessidade de abordá-la "para além do modelo marxista". Ressaltando a importância de não se naturalizar as relações sociais, o documento explicita que "nem em Durkheim encontramos essa aceitação" (grifos nossos). No primeiro caso, Marx é tratado como um autor a ser superado. No segundo, Durkheim é visto como um autor de menor porte, quase ingênuo. 
Embora as referências a Weber não sejam tão evidentes nas OCN (BRASIL, 2006), é possível constatar a inclinação teórica por este autor neste documento. A princípio, o material defende a diversidade teórica, ao argumentar que os clássicos são complementares e que existem "intersecções” entre eles. Nesse sentido, o documento sustenta que "(...) há entre esses autores 'vazios teóricos', isto é, fenômenos de que suas teorias não dão conta, quer pela inexistência de tais fenômenos na época quer pelos limites da própria teoria" (idem, p. 18).

O principal fundamento epistemológico do documento está presente nos conceitos de "estranhamento" e "desnaturalização". Nesse sentido, explicita que "um papel central que o pensamento sociológico realiza é a desnaturalização das concepções e explicações dos fenômenos sociais" e que a atitude de estranhamento é a que permite "observar que os fenômenos sociais que rodeiam a todos e dos quais se participa não são de imediato conhecidos, pois aparecem como ordinários, triviais, corriqueiros, normais". Em seguida, destaca conceitos como historicidade, deixando claro o ponto de partida na sociologia do conhecimento de Peter baseado no conceito "construção social da realidade" (BERGER, LUCKMANN, 1973). Como se sabe, esta noção supõe a separação entre ciência e "conhecimento" do senso comum, e nas concepções weberianas de "objetividade" e "neutralidade axiológica" do conhecimento", ou seja, na necessidade de separação entre ciência e política (WEBER, 1967). ${ }^{10}$

Outro elemento importante de ser destacado nas OCN é o que se refere aos "pressupostos metodológicos" para o ensino de Sociologia, que propõe três dimensões necessárias para a construção das propostas curriculares: teorias, conceitos e temas. $\mathrm{O}$ documento sustenta que as teorias correspondem à dimensão explicativa ou compreensiva, os conceitos à dimensão lingüística ou discursiva, e os temas à dimensão empírica ou concreta. Assim, critica a idéia de trabalhar separadamente esses três eixos e defende que se deve "tomar um deles como 'centro' e os outros como referenciais", apresentando vantagens e desvantagens em cada ponto de partida. Retomaremos este ponto mais adiante.

A abordagem weberiana dos conceitos de "estranhamento" e "desnaturalização" ficam mais claras nos Cadernos e na Proposta Curricular de Sociologia do Estado de São Paulo (SEE/SP, 2009a, 2009b). Os Cadernos definem o recurso metodológico do estranhamento como "afastamento" e "crítica" a tudo que parece "natural", "verdadeiro" e "definitivo", ou ainda, "a atitude de distanciamento ante a realidade do aluno". Ao discorrer sobre os fundamentos do conhecimento científico, afirma que este precisa "ir além do senso comum". Nesse sentido, apresenta a seguinte argumentação: "Nosso olhar nunca é um olhar neutro, ele está sempre repleto dessas prenoções que vêm do senso comum. Para lançar um olhar sociológico para a realidade é necessário afastar-se dessa forma de observá-la". Porém, mesmo reconhecendo a impossibilidade da neutralidade no ponto de partida do conhecimento científico, ou seja, na escolha do objeto, observa que "A ciência se constrói a partir de um cuidado metodológico ao olhar a realidade que procura se afastar dos juízos de valor típicos do senso comum". Ou ainda: "Se quisermos construir um conhecimento coerente e consistente, precisamos afastar as prenoções e os julgamentos de valor que estão presentes no senso comum. $\mathrm{O}$ olhar que evita essas posturas relacionadas ao senso comum é o olhar do estranhamento". Na Proposta Curricular, este pressuposto epistemológico fica mais claro na seguinte afirmação: "O ensino de Sociologia pressupõe, então, a compreensão da educação como um caminho para conhecer, para saber, no sentido de superar os preconceitos, as ideologias, o senso comum; enfim, para desenvolver a capacidade crítica" (grifo nosso). Sendo assim, em linhas gerais, a Proposta Curricular e os Cadernos de Sociologia do estado de São Paulo estão orientados pela noção de neutralidade axiológica e pela separação entre ciência e política na construção da 
"objetividade" do conhecimento nas Ciências Sociais, concepções caras à Sociologia de Weber. ${ }^{11}$

O livro de Bomeny e Medeiros (2010), indicado pelo PNLD, utiliza o filme Tempos Modernos, de Chaplin, como "operador metodológico". A Parte II (“A sociologia vai ao cinema") é composta por oito capítulos e cada um deles se inicia com a descrição de uma cena do filme, utilizada como "mote" para apresentar cada um dos pensadores que as autoras consideram essenciais. Assim, são tratados, nesta ordem: Durkheim, Weber, Simmel, Marx, Tocqueville, Foucault, Elias e Benjamin. O fio condutor do material está baseado na noção de diversidade das teorias sociológicas. Trabalha, portanto, com a idéia segundo a qual a Sociologia no Ensino Médio deve proporcionar um conhecimento mínimo dos autores considerados mais importantes. Ao explicitar sua metodologia de ensino e aprendizagem, Bomeny e Medeiros (2010) insistem sobre a necessidade de se afastar da "noção ainda muito presente na educação brasileira de que os alunos são meros receptores de conteúdos prontos". Consideram, nesse sentido, que "o repertório cultural dos estudantes deve ser considerado" e que "o conteúdo do livro procura dialogar com as redes e experiências sociais dos alunos, tomadas como fontes ricas que permitem fazer de cada aula em um verdadeiro laboratório de sociologia". Para fundamentar sociologicamente este pressuposto pedagógico, as autoras utilizam o conceito de "imaginação sociológica" de Wright Mills, referência importante na fundamentação teórica pelos demais manuais didáticos consultados. Nesse sentido, Bomeny e Medeiros sustentam que o "projeto cultural da disciplina" consiste em "estabelecer as conexões entre as experiências individuais (biografias) e a vida em sociedade (história)". É possível afirmar que o conceito de "imaginação sociológica" foi desenvolvido com base nos postulados epistemológicos weberianos, na medida em que busca estabelecer uma conexão entre o cotidiano e a realidade social a partir de um distanciamento dos valores, e na medida em que tem como ponto de partida da reflexão sociológica a ação social dos indivíduos (Mills, 2009, pp. 84-87). Nesse sentido, é possível afirmar que a orientação epistemológica mais geral das autoras é de matriz weberiana.

O livro de Tomazi (2011) parte da mesma concepção de "estranhamento" e "desnaturalização" presentes nos demais documentos. Por exemplo, ao questionar, no Manual do Professor "como manter o distanciamento necessário para a apreensão científica do real?", argumenta que é necessário "colocar-se a distância do fenômeno social - ainda que este faça parte da experiência do pesquisador - é a possibilidade de ultrapassar os limites do senso comum, que supõe a naturalidade da cultura, e inquietar-se com questões rotineiras e consagradas pela normalidade" (TOMAZI, 2011, p. 6). ${ }^{12}$

Ao defender a "diversidade teórica" na abordagem da disciplina, Tomazi afirma que "a Sociologia oferece várias possibilidades teóricas para a análise da relação entre indivíduo e sociedade" e "A diversidade de análises é um dos elementos essenciais do pensamento sociológico". Na Unidade 1 (“A sociedade dos indivíduos”, mesmo título do livro clássico de Norbert Elias), o autor busca traçar um panorama geral de como a questão das relações entre indivíduo e sociedade foi tratada na história da Sociologia. Aborda, a princípio, os três clássicos, sistematizando-os da seguinte maneira: "Para Marx, o foco recai sobre os indivíduos inseridos nas classes sociais. Para Durkheim, o fundamental é a sociedade e a integração dos indivíduos nela. Para Weber, os indivíduos e suas ações são os elementos constitutivos da sociedade". Em seguida, conclui que: "Dois autores contemporâneos analisaram a relação entre indivíduo e sociedade procurando integrar esses pólos". A partir dessa afirmação, o autor apresenta o conceito de configuração, de Norbert Elias, e de habitus, de Bourdieu, que supostamente teriam buscado pensar essa relação de "forma dinâmica", superando seus predecessores. 
A questão suscitada pelo autor levanta uma polêmica. Ao contrário do que afirma Tomazi, sustentamos que tanto em Marx, como em Durkheim e Weber é possível identificar um complexo dinamismo na maneira como concebem a relação entre indivíduo e sociedade. Por exemplo, nas Teses sobre Feuerbach, Marx encontra uma forma bastante sofisticada de tratar a indissociabilidade entre indivíduo e sociedade ao expor os pressupostos do materialismo histórico e sua superação dialética entre o materialismo feuerbachiano e o idealismo de Hegel. ${ }^{13}$ Sendo assim, a discussão sociológica sobre a relação entre indivíduo e sociedade feita por Tomazi parte de uma premissa que compromete o desenvolvimento de seu argumento, pois se apóia em uma visão insuficiente, porém muito difundida por alguns autores da Sociologia contemporânea que reduz Durkheim a um funcionalismo mecanicista, Marx a um determinismo econômico, e Weber a um individualismo psicologizante.

Tal como já anunciamos, vale questionar se é objetivo da Sociologia no Ensino Médio tratar a diversidade teórica de seu campo a partir de um debate eminentemente acadêmico (tal como se faz na universidade), correndo-se o risco de expor os autores a um inevitável reducionismo. ${ }^{14}$ Não cabe dúvida de que é necessário explicitar, a título introdutório, a existência dessa diversidade, procedimento fundamental para problematizar a relação entre ciência e ideologia. Mas, somente se evita o tratamento reducionista dos autores se a posição epistemológica adotada (pelo autor de um manual ou pelo professor) for aplicada em estado prático, ao longo dos capítulos ou das aulas, no tratamento das diferentes temáticas, tal como fazem os livros didáticos das disciplinas com maior tradição escolar. O debate teórico-metodológico na Sociologia não é mais complexo do que na História. Porém, não existe uma preocupação dos manuais dessa disciplina em apresentar as interpretações dos eventos históricos de acordo com cada corrente historiográfica ou a teoria da história, ou segundo cada autor clássico. ${ }^{15}$ Este debate, de cunho acadêmico, é necessário na universidade, mas perde o sentido no Ensino Médio devido à natureza do processo pedagógico neste nível de aprendizagem (em que cada disciplina conta com poucas horas de estudo). Ademais, não é o único recurso possível para se problematizar a noção de neutralidade da ciência e da diversidade de interpretações da realidade. Pelo que foi dito até aqui, o ponto de partida nos temas para se chegar aos conceitos por meio de uma teoria específica evita o reducionismo analítico na abordagem baseada na noção de "diversidade teórica" fundante do pensamento sociológico. Essa questão ficará mais clara no terceiro item deste artigo.

A despeito das diferenças de concepção pedagógica e de abordagem sociológica dos conceitos trabalhados, os PCN, as OCN, a Proposta Curricular do estado de São Paulo, os Cadernos de Sociologia, e os livros Tempos Modernos, Tempos de Sociologia e Sociologia para o ensino médio partem de uma matriz epistemológica comum. No caso dos PCN a preferência por Weber no repertório conceitual é clara. No caso dos demais documentos, o ponto de partida geral é o conceito de estranhamento e desnaturalização da realidade, que se fundamentam na concepção weberiana de "objetividade" e "neutralidade axiológica" do conhecimento nas Ciências Sociais. Vale ressaltar também que os manuais e propostas analisadas estão fundamentados na necessidade de articulação entre teorias, conceitos e temas. Buscaremos sustentar que este pressuposto está na base de algumas das principais dificuldades apontadas pela bibliografia que trata o ensino de Sociologia. Antes problematizar essas questões, será feita uma sistematização dos principais fundamentos da PHC, que segundo nossa hipótese, é uma teoria educacional e pedagógica que pode contribuir para superar essas dificuldades. 


\section{2) A Pedagogia Histórico-Crítica}

A Pedagogia Histórico-Crítica (PHC) é uma teoria educacional e pedagógica que se inspira na concepção marxista de educação e sociedade. ${ }^{16}$ Não é objetivo deste artigo reconstituir todo o contexto que deu origem a esta teoria, o que exigiria uma exposição exaustiva das concepções educacionais com as quais debate Saviani, divididas por ele em pedagogias não críticas (Pedagogia Tradicional, Pedagogia Tecnicista e Escola Nova) e pedagogias crítico-reprodutivistas (Teoria do Aparelho Ideológico de Estado, de Althusser, Teoria da Escola Dualista, de Baudelot e Establet, e Teoria da Violência Simbólica, de Bourdieu e Passeron). ${ }^{17}$ Vale a pena, no entanto, fazer menção a alguns aspectos deste debate a fim de contextualizar o objetivo geral da PHC. Uma leitura preliminar das críticas feitas por Saviani a essas teorias pode levar a uma primeira impressão de que: (1) o autor reúne, em sua tipologia, correntes teóricas muito distintas, o que acarreta certo reducionismo analítico e; (2) o autor nega os avanços da análise crítica do caráter de classe da educação por conta do adjetivo aparentemente depreciador "reprodutivista". A nosso ver, essas críticas não procedem. O propósito de Saviani nessa classificação era destacar que enquanto as teorias não-críticas não problematizam criticamente a relação entre educação e sociedade, as teorias crítico-reprodutivistas o fazem, porém, enfatizando o papel da educação como espaço de reprodução, mas não de possível transformação das relações sociais. Nesse sentido, ao se constituírem como teorias educacionais, mas não como teorias pedagógicas $^{18}$, as teorias crítico-reprodutivistas enfatizavam o papel da escola para a reprodução das classes sociais, mas se colocavam o objetivo de explorar as potencialidades do sistema escolar e do trabalho pedagógico em sala de aula.

Para a PHC não existe conhecimento desinteressado, mas diferentes vínculos entre os saberes e as posições que os agentes tomam em relação às situações históricas concretas. Desse modo, assim como a ciência, a atividade pedagógica também não é neutra. O principal objetivo da PHC é vincular a prática pedagógica com a prática social global, a partir do percurso dialético prática-teoria-prática. Trata-se de uma proposta didática fundada no materialismo histórico, que visa não apenas mudanças acidentais (reformas), mas a transformação estrutural da sociedade (revolução). Desse modo, levando em conta que a educação se dá no interior da prática social, esta se torna um suporte do processo pedagógico. Ademais, teoria e prática formam uma unidade indissociável e, portanto, devem estar intencionalmente articuladas a partir de finalidades políticas delimitadas. Desse modo, a aprendizagem deve ser significativa não só para a vida imediata (o cotidiano e as experiências) dos alunos, mas para a transformação da prática social na qual estes estão inseridos. Inspirando-se especialmente em Marx, Lênin e Gramsci, Saviani desloca o centro dos processos pedagógicos para a prática social global e, a partir da noção de que todo conhecimento deve ser interessado e transformador, propõe que a escola exerça um papel de mediação no seio da prática social. ${ }^{19}$ Outra idéia central de Saviani é de que o objetivo histórico da educação é a socialização dos instrumentos educacionais para que as classes subalternas possam ingressar na cultura letrada. ${ }^{20}$ Para tanto, é necessário uma mudança radical na estrutura organizacional da escola (a começar pela proposta pedagógica), mediada por uma mudança estrutural da sociedade, para que os dominados possam dominar o que os dominantes dominam: o conhecimento científico.

A PHC recebe a crítica freqüente de que sua proposta é conteudista por, supostamente, centrar o processo educacional no professor, que se encarrega de expor os conteúdos de modo heterônomo, tal como no Ensino Tradicional. Para a PHC, o domínio dos conteúdos é necessário para o acesso ao saber científico, que é um meio de produção. Nesse sentido, é um dos principais instrumentos de poder do capital. Não sendo possível 
que o conhecimento acumulado pela humanidade seja adquirido espontaneamente, é necessária a mediação do professor entre o objeto do conhecimento (os conteúdos) e os sujeitos do conhecimento (os alunos), que por meio da ressignificação da prática social global, adquirem os meios necessários para um posicionamento crítico diante da realidade $^{21}$. Ora, as discussões pedagógicas que enfatizam as mudanças no método sem levar em conta as finalidades às quais este está subordinado não se fundamentam a necessidade de mudanças estruturais: admitem que a sociedade é dinâmica e que a escola é parte de sua estrutura, mas não buscam as mudanças necessárias para a transformação radical da sociedade. Para a PHC, no processo educacional a finalidade (a qual guia o método, e não o contrário) é a transformação da estrutura da sociedade.

Um dos objetivos da PHC é tratar a relação entre professor e aluno de forma dialética. Segundo esta concepção, a lógica formal pode fazer o caminho da síntese, como no raciocínio do silogismo, mas não o faz de maneira superadora. Ao contrário, a lógica dialética busca identificar os elementos e as múltiplas relações que se estabelecem numa visão de unidade, na qual a teoria e a prática são processos inerentes na busca de superação das contradições. No processo pedagógico, opõe a teoria ao verbalismo; e a prática ao ativismo. Para construir estes fundamentos, a PHC encontra uma correspondência teórica com o método da Economia Política exposto por Marx (1974) e com a noção de sujeito desenvolvida por Vigotsky $(1998 \mathrm{a}, 1998 \mathrm{~b}) .{ }^{22}$ O método marxista tem como ponto de partida o real. Esse real não é ainda o real concreto, mas um real representado na intuição, ou seja, uma manifestação empírica aparente, do mundo sensível, uma representação caótica da realidade. O exemplo dado por Marx é o estudo da população, que em um primeiro momento aparece como uma somatória de indivíduos, um emaranhado confuso e caótico, apropriado apenas de maneira espontânea pelo senso comum. Segundo Marx, para desenvolver sua análise o investigador deve decompor este real aparente em partes. No estudo da população, deve encontrar suas classes, a divisão social do trabalho, como se dá a produção, a distribuição, a troca e o consumo. Por último, deve partir dessas determinações simples, voltar ao real e sistematizar o conhecimento como uma rica totalidade de múltiplas determinações.

O método de Marx consiste em partir do empírico (concreto figurado) para chegar ao concreto pela mediação da abstração. Ou seja, deve partir da síncrise para se chegar à síntese pela mediação da análise. Ou ainda, deve partir da análise do empírico para chegar à síntese do concreto. Desse modo, o materialismo dialético marxiano busca resolver os principais problemas postos pela filosofia de sua época, ao superar os métodos baseados na indução (empirismo) e na dedução (racionalismo). Para tanto, parte do método indutivo (juízo sintético, que vai do particular para o geral), baseado na descrição do real aparente para elaborar enunciados e teorias por meio do método dedutivo (juízo analítico, que vai do geral para o particular), e assim chegar à essência do real, visto como uma totalidade sintética de múltiplas determinações articuladas, ou seja, uma unidade da diversidade, contraditória e multifacetada. Assim, o concreto real, que aparece no ponto de partida como suporte da observação imediata e, portanto, uma representação das impressões sensíveis (totalidade caótica), no ponto de chegada se torna concreto pensado, que é uma síntese para o pensamento (totalidade concreta). É necessário, pois, chegar aos conceitos, para proceder ao caminho de volta de análise do real, embora se trate do mesmo real, dessa vez, como produto do pensamento. Nessa reconstituição é que se atinge a síntese. Em outras palavras, o método de Marx consiste em elevar o empírico ao estatuto de concreto pela mediação da abstração. Enquanto a representação por meio da observação é uma determinação abstrata, por meio do pensamento esta atinge o nível de concreto pensado. Portanto, o concreto não é o produto do pensamento, mas de condições históricas reais. 
Trata-se, portanto, de um realismo crítico que visa se opor ao realismo "ingênuo", ahistórico. Desse modo, para Marx, assim como o concreto é um conjunto de relações históricas reais particulares, o abstrato é um conjunto de relações reais históricas gerais. $\mathrm{O}$ autor articula, portanto, empirismo e idealismo como dois momentos da análise. Por isso, a totalidade do concreto do pensamento só é possível por meio da elaboração de conceitos a partir da observação imediata e da representação. ${ }^{23}$

A partir do referencial teórico de Marx, Gramsci e Vigotsky, Saviani busca colocar o objetivo final do processo pedagógico em sair do "senso comum" para se chegar à "consciência filosófica" pela mediação da práxis. Tal proposta dialética resolveria os principais dilemas filosóficos em torno de dois dualismos presentes nas discussões científicas: espontaneísmo x empirismo (na visão de ser humano); idealismo metafísico $\mathrm{x}$ materialismo mecanicista (na visão de sociedade). Nas discussões educacionais, essas referências servem para articular os processos pedagógicos ora centrados no aluno e em sua ação, ora no professor e em sua exposição, por meio de uma mediação com a prática social na qual o sujeito e o objeto do conhecimento estão envolvidos. Ao superar essa dicotomia, Saviani propõe um procedimento pedagógico correspondente ao método marxiano que passa por um duplo percurso dialético entre transmissão (professor-alunoprofessor) e assimilação (aluno-professor-aluno).

O método da PHC se desdobra em cinco passos: A) Prática Social Global, B) Problematização, C) Instrumentalização, d) Catarse e E) Prática Social Global. Antes de desenvolver um breve resumo das características de cada uma dessas etapas, vale fazer algumas aclarações. É importante levar em conta que a didática não corresponde a passos sucessivos, e a regras, pois os diferentes momentos podem se desenvolver de maneira concomitante. Em segundo lugar, é importante destacar que os cinco passos da PHC buscam superar as etapas das principais teorias que critica, embora não sejam homólogos a estas. ${ }^{24}$ Em resumo, a Prática Social no início da atividade pedagógica seria uma síntese entre a Preparação e a Atividade; a Problematização, uma síntese entre a Apresentação e o Problema; a Instrumentalização, uma síntese entre a Assimilação e a Coleta de Dados; a Catarse uma síntese entre a Generalização e a Hipótese; e a Prática Social, no final da atividade pedagógica, uma síntese entre a Aplicação e a Experimentação. ${ }^{25}$ Sendo assim, o objetivo é que a educação seja uma mediação no seio da prática social global. Passamos à descrição das etapas da PHC.

A) A Prática Social Global é o ponto de partida do processo de ensino-aprendizagem, em que o professor tem contato com os conhecimentos prévios dos alunos e sua articulação com o real. Aqui o docente pode detectar a desigualdade real existente entre seu saber e o aluno, bem como a igualdade possível no final do processo pedagógico. Em termos vigotskyanos, é o momento em que, por meio da expressão de algo que ocorre na sociedade, o professor pode detectar o nível de desenvolvimento real e o nível de desenvolvimento potencial para chegar à zona de desenvolvimento proximal (ou iminente) na qual sua prática se baseará. Nesta fase, o docente deve apresentar para a turma as questões que serão norteadoras do projeto pedagógico a ser desenvolvido.

B) Durante a Problematização, as questões postas pela prática social se transformam em problemas desafiadores. É o momento em que professor e aluno se aproximam ao conteúdo que será trabalhado buscando fazer uma primeira mediação do conhecimento, ainda que caótica e não sistemática.

C) Em seguida, na Instrumentalização, devem ser trabalhados os instrumentos teóricos e práticos para o equacionamento das questões levantadas pela prática social e problematizadas por alunos e professores. É o momento em que os conteúdos e os conceitos são trabalhados. Neste momento se dá a interação entre o sujeito do 
conhecimento (aluno) e o objeto do conhecimento (conteúdo) proporcionada pelo mediador do conhecimento (professor).

D) $\mathrm{Na}$ Catarse o aluno deve mostrar como se apropriou do conteúdo. É o ponto culminante do processo, pois se chega à síntese das múltiplas determinações trabalhadas durante o processo de ensino-aprendizagem. Empregado em termos gramscianos, significa a assimilação subjetiva das condições objetivas, a incorporação pelos sujeitos dos elementos culturais desenvolvidos historicamente, ou ainda, a assimilação superior da estrutura em superestrutura na consciência. Nesse momento, acontece a passagem das objetivações em si para as objetivações para si, processo este que é irreversível, pois significa que se atingiu um nível mais elevado de consciência (Gramsci, 1978). ${ }^{26}$

E) Por fim, voltando para a Prática Social, aluno e professor podem reconstruir o conhecimento dos fatores condicionantes da realidade. Trata-se do momento em que as ações e intenções de docentes e discentes podem ser colocadas como forma de demonstrar a disposição para a transformação do real com base em uma nova postura diante do saber científico.

Para a PHC, o conhecimento se constrói a partir de um saber objetivo e do aluno concreto, não do aluno empírico. ${ }^{27}$ No encontro entre saber espontâneo e saber científico, deve-se partir da prática social para que a aprendizagem seja significativa. Assim, o objetivo da prática pedagógica é criar necessidades (motivos) e o método passa a ser um meio subordinado a este fim.

Essa descrição teve o sentido de situar o leitor em relação aos pressupostos epistemológicos da PHC. Vejamos a seguir quais são suas implicações para a problematização das propostas didáticas para a Sociologia apresentadas no item anterior.

\section{III) O Ensino de Sociologia e a Pedagogia Histórico-crítica}

De que maneira os pressupostos da PHC podem contribuir para a superação de alguns limites e dilemas que vêm sendo identificados para a matéria de Sociologia no Ensino Médio? Antes de apresentar nossos argumentos, vale, neste momento da exposição, tecer algumas considerações sobre a questão inversa: por que a Sociologia é uma matéria indispensável para a PHC? Enquanto as demais ciências com tradição escolar podem ser abordadas em sala de aula a partir da mediação entre seus conteúdos e a prática social (inserindo os temas em sua dimensão histórico-social), a Sociologia tem como objeto de estudo a própria prática social global, ou seja, tem esta como "pretexto" e "contexto". Sendo assim, como disciplina científica e também como matéria escolar, cumpre uma função epistemológica essencial na compreensão das relações sociais nas quais os sujeitos (e os diferentes campos do saber) estão inseridos, o que é coerente com os objetivos da $\mathrm{PHC}^{28}$

Retomando a questão inicial, argumentarei a seguir que a PHC pode ser uma alternativa às formas predominantes da abordagem sociológica e pedagógica dos documentos oficiais e dos materiais didáticos analisados. Sistematizarei os argumentos a partir de quatro elementos tratados em nossa crítica às propostas curriculares: 1) o conceito de estranhamento e desnaturalização; 2) o dilema em torno do ponto de partida, se em temas, teorias ou conceitos; 3 ) o tratamento da "diversidade teórica" de seus autores. Antes de iniciar a análise desses pontos, vale destacar um quarto elemento, muito citado entre os estudiosos das práticas de ensino de Sociologia ${ }^{29}$, e que aqui denominaremos como 4) a oposição entre verbalismo e ativismo pedagógico. Vale expor alguns comentários adicionais sobre essa questão. 
Casão e Quinteiro (2007, p. 237) observam que boa parte dos professores opta por um "ensino abstrato, academicista, que contempla apenas teorias e conceitos, sem vinculação com temas do cotidiano". Jinkings (2007, p. 126-127) identifica que, "utilizando textos da grande imprensa, vários desses professores convertem as aulas de Sociologia em discussão de atualidades", "sem uma superação das explicações de senso comum" e que "outros desses professores apresentam em sala de aula conceitos tomados como estáticos, desconectados das teorias clássicas e dos princípios explicativos básicos das ciências sociais" (grifos meus) ${ }^{30}$ A primeira estratégia se identifica com o verbalismo, e a segunda, ao ativismo pedagógico. Segundo nossa hipótese, a PHC fornece algumas ferramentas para superar este problema.

O conceito de desnaturalização e estranhamento, tal como apresentado pelos documentos e manuais analisados, está fundamentado no resquício positivista da teoria de Weber, segundo o qual a objetividade do conhecimento nas Ciências Sociais pressupõe a separação entre ciência e política, devendo o investigador se ater ao "cuidado metodológico" de se distanciar do conhecimento do senso comum, bem como de seus valores e ideologias. A PHC se fundamenta no pressuposto marxista da indissociabilidade entre ciência e política e ressalta o caráter ideológico de classe do conhecimento científico e escolar. Por isso, destaca a necessidade de o professor assumir as consequiências políticas presentes nos recortes propostos e no tratamento teórico dos conteúdos trabalhados. Nesse sentido, não pressupõe a possibilidade de um conhecimento e de uma metodologia neutra, mas busca problematizar a prática social a partir de uma mediação pedagógica entre o objeto e o sujeito do conhecimento.

A PHC busca resolver o dilema da referência em temas, conteúdos ou conceitos priorizando o ponto de partida nos temas relevantes para problematizar a prática social global na qual os alunos estão inseridos. $\mathrm{O}$ objetivo do tratamento dos temas deve ser a aquisição de conceitos para que, no processo de catarse, estes possam estabelecer novas relações de mediação com a prática social global. A mediação entre os temas e os conceitos deve ser feita pela teoria, que corresponde à articulação abstrata necessária entre o conhecimento empírico e as situações concretas. Uma vez trabalhados em sala de aula, os temas devem ter como objetivo o desenvolvimento de conceitos operados por meio de um marco teórico específico, o que permite aprofundar o conceito não só do ponto de vista de sua definição, mas de sua aplicação a partir da relação entre o sistema teórico geral e a prática social global.

Mas, se a Sociologia como ciência pressupõe uma diversidade de teorias, por que ensiná-la, como matéria escolar, a partir de um marco teórico específico? Para responder a esta questão, é necessário identificar alguns limites do "ecletismo didático": 1) o tratamento equânime dos autores e teorias se torna limitado pela reduzida carga horária da disciplina $^{31}$; 2) nos capítulos temáticos dos manuais, certas correntes sempre são priorizadas em detrimento de outras ${ }^{32}$; 3) a diversidade conceitual tende a confundir os alunos, já que as definições conceituais (geralmente em um nível de abstração epistemologicamente incompatível com o público prioritariamente adolescente) não levam em conta o enquadramento dos conceitos no sistema teórico dos autores; 4) o debate entre teorias, que é objeto de discussões acadêmicas, tende a ser simplificado por meio de um esquematismo simplista, contribuindo para um reducionismo analítico incontornável.

A PHC busca problematizar a prática social, identificando os pressupostos políticoideológicos do conhecimento, e partindo de temas para desenvolver conceitos pela mediação da teoria. Este fundamento possui como conseqüência didática a necessidade de superação da oposição entre o verbalismo e o ativismo. Tal como já chamamos a atenção, embora muitas experiências vêm tentando superar essa dicotomia, ainda tem sido muito 
comum aulas de Sociologia no Ensino Médio baseada em conhecimentos gerais baseados na visão do senso comum ou em uma exposição enciclopédica de autores e conceitos esvaziados de sentidos para os alunos. O conceito de prática social permite ir além tanto da noção de experiências, saberes prévios e cotidiano (que subsume o conhecimento escolar ao conhecimento tácito) como do método baseado na exposição de conceitos e teorias distantes dos educandos (que subsume o conhecimento escolar ao conhecimento científicoacadêmico). Apesar do esforço de articular a realidade do estudante aos conceitos sociológicos, a adequação pedagógica do conceito de "imaginação sociológica" de Mills (2009, pp. 84-87), como fazem Bomeny e Medeitos, apresenta significativas diferenças em relação à perspectiva da PHC. Nesta última, a mediação pedagógica não é entre biografia e história, mas entre a prática social (história) e o conceito, sendo que o primeiro é a própria mediação entre biografia e história; e o segundo, a mediação entre o conhecimento empírico e a abstração teórica.

O ponto de partida na prática social, ou seja, na inserção dos sujeitos nos grupos e nas classes sociais, permite uma problematização dos conflitos e dos antagonismos coletivos, para que seja possível identificar quais são os conceitos necessários para a instrumentalização dos alunos, a fim de que no processo de catarse, a prática social seja ressignificada a partir de um novo estágio de consciência. Não se trata de negar a importância do relato das experiências individuais, ou da utilização de textos jornalísticos nas aulas de Sociologia, mas de ressaltar o papel necessário da mediação do professor. Dessa maneira, os relatos individuais não devem ser tomados para sustentar o relativismo ilimitado do conhecimento, assim como as aulas expositivas não devem ser realizadas em função do tratamento estático dos conceitos, de modo que estes se tornem universais a tal ponto que jamais possam ser ressignificados pelas experiências particulares. Por isso, o conhecimento empírico deve receber um tratamento teórico a partir da análise da prática social para que se torne conhecimento concreto.

\section{Considerações finais}

Procuramos argumentar ao longo deste artigo que as atuais propostas curriculares para a Sociologia, presentes nos documentos oficiais e nos materiais didáticos tem se guiado nos fundamentos epistemológicos da sociologia weberiana. Este referencial fica evidente no tratamento dado aos conceitos de estranhamento e desnaturalização, que partem da noção de separação entre ciência e política (e entre conhecimento científico e conhecimento de senso comum) e no postulado da "neutralidade axiológica" e "objetividade" do conhecimento nas Ciências Sociais. Transferida para o plano de organização didática, as propostas curriculares vem priorizando a abordagem da "diversidade teórica" da disciplina, apresentando suas diferentes correntes para justificar uma posição neutra de não tomar posição diante de nenhuma delas, ao menos de modo explícito. Por conta da necessidade de tratar os diferentes autores, apresenta-se uma dificuldade em articular temas, teorias e conceitos, já que, apesar da complexidade do debate acadêmico que o sustenta, a carga horária é reduzida para atingir tal objetivo. Por um lado, ao não se levar em conta as diferenças epistemológicas essenciais entre a Sociologia como disciplina científica e como matéria escolar, acaba-se por fazer uma transposição mecânica de seus conhecimentos produzidos na academia. Por outro, partindo da noção de "imaginação sociológica" e "construção social da realidade", pretende-se valorizar as experiências individuais prévias dos alunos no processo de construção do conhecimento. Resultado: as aulas oscilam entre o verbalismo da exposição das teorias e conceitos, e o "ativismo" baseado no que os alunos acham sobre determinados temas. 
A PHC, teoria educacional e pedagógica desenvolvida por Dermeval Saviani, pode cumprir um papel fundamental na superação dessas dificuldades, tendo em vista que seus passos pedagógicos e finalidades buscam conciliar a relação entre o sujeito do conhecimento (o aluno) e o objeto do conhecimento (os conteúdos) a partir da intervenção do mediador do conhecimento (o professor). Ao estabelecer a prática social global como a mediação necessária em sala de aula, no ponto de chegada e de partida da construção do conhecimento, a PHC permite desenvolver uma alternativa aos principais dilemas e dificuldades identificadas nas atuais propostas para o ensino de Sociologia: a neutralidade axiológica, a diversidade teórica, o dilema na articulação entre temas, teorias e conceitos, e a tensão entre o verbalismo e o ativismo. Ao contrário dos pressupostos epistemológicos weberianos presentes na noção de estranhamento e desnaturalização, a PHC parte da noção de que ciência e política são indissociáveis. Tanto a atividade científica como a atividade educativa não podem ser neutras ou desinteressadas. Se por um lado existe a diversidade teórica na construção da ciência (fundamental para a discussão acadêmica aprofundada de um campo disciplinar), por outro é necessário reconhecer a importância da tomada de posição e da escolha teórico-metodológica para tratar os temas sem cair em reducionismo analítico na prática pedagógica (prejudicial para o aluno do Ensino Médio que está limitado a um contato muito elementar com as diversas matérias escolares). Por isso o tratamento por temas é o meio para se buscar um vínculo entre teoria e conceitos de um marco teórico específico, tal como vem sendo feito nas disciplinas de maior tradição escolar, onde as propostas curriculares estão em disputa, cada uma fundamentada a partir de uma escolha prévia. Essa forma de abordar a disciplina permite superar o verbalismo e o ativismo pedagógico, uma vez que os conteúdos são tratados de forma crítica em sua relação com a prática social em que os estudantes estão inseridos, superando a dicotomia entre conteúdos vazios e a abordagem de senso comum baseada nas experiências individuais.

\section{Referências}

BERGER, P.; LUCKMANN, T. A construção social da realidade. Rio de Janeiro: Vozes, 1973.

BOMENY, H.; MEDEIROS, B. F. Tempos modernos, tempos de Sociologia. São Paulo: Editora do Brasil, 2010.

BRASIL. Ministério da Educação. "Conhecimentos de Sociologia”. (p. 101-133). In:

Orientações Curriculares Nacionais. (Vol. 3, Ciências Humanas e suas Tecnologias). Brasília: Ministério da Educação, Secretaria de Educação Básica, 2006.

BRASIL. Ministério da Educação. "Conhecimentos de Sociologia, Antropologia e Política". In: Parâmetros Curriculares Nacionais (Ensino Médio). Parte IV: Ciências Humanas e suas Tecnologias. Brasília: Ministério da Educação, Secretaria de Educação Básica, p. 36-43, 1998.

CASÃO, C. D. C. e QUINTEIRO, C. T. Pensando a Sociologia no ensino médio através dos PCNEM e das OCNEM. Mediações, Londrina, v. 12, pp. 225-238, 2007.

COHN, G. "Introdução". In: Weber - Sociologia. 2a ed. (Coleção Grandes Cientistas Sociais). São Paulo: Editora Ática, 1982. 
DUARTE, N. "Conhecimento Tácito e Conhecimento Escolar na Formação do Professor (Porque Donald Schön não entendeu Luria)". Educação e Sociedade, Campinas, vol. 24, n. 83, p. 601-625, 2003.

FREITAG, B. Escola, Estado e Sociedade. São Paulo: Edart, 1978.

FARIA, Ana Lúcia G. Ideologia e livro didático. São Paulo: Cortez Editora; Autores Associados, 1984.

GRAMSCI, A. Os intelectuais e a organização da cultura. Rio de Janeiro: Civilização Brasileira 1968.

GRAMSCI, A. Concepção dialética da história. $2^{\mathrm{a}}$ ed. Rio de Janeiro: Civilização Brasileira, 1978.

HANDFAS, A.; TEIXEIRA, R. C. "A prática de ensino como rito de passagem e o ensino de Sociologia nas escolas de nível médio”. Mediações, Londrina, v.12, n.1, p. 131-142, jan./jun, 2007.

JINKINGS, I. Ensino de sociologia: particularidades e desafios contemporâneos.

Mediações, Londrina, v.12, n.1, p. 113-130, jan./jun, 2007.

LÊNIN, V. I. Que fazer? São Paulo: Hucitec, 1978.

LÖWY, M. Ideologias e ciência social: elementos para uma análise marxista. São Paulo: Cortez, 1985.

MARX, K. Contribuição para a crítica da economia política. Lisboa: Editorial Estampa, 1974.

MARX, K. O Capital. São Paulo: Abril Cultural, 1982.

MARX, K. Teses sobre Feuerbach. Em: Marx, K; Engels, F. A ideologia alemã. $10^{\text {a }}$. Ed, São Paulo: Editora Hucitec, 1996.

MILLS, C. W. Sobre o artesanato intelectual e outros ensaios. Rio de Janeiro: Jorge Zahar Editores, 2009.

SAVIANI, D. A pedagogia no Brasil: história e teoria. Campinas: Autores Associados, 2008a.

SAVIANI, D. Escola e democracia, 41 a ed. Campinas: Autores Associados, 2009.

SAVIANI, D. Pedagogia histórico-crítica: primeiras aproximações $\left(10^{\mathrm{a}}\right.$ ed. revista e ampliada). Campinas: Autores Associados, 2008b.

SCALCON, S. G. À procura da unidade psicopedagógica: articulando a psicologia histórico-cultural com a pedagogia histórico-crítica. Campinas: Autores Associados, 2002.

SEE/SP. Sociologia - Caderno do Professor $-\mathbf{1}^{\mathbf{a}}$ série, v. 1. São Paulo: Secretaria da Educação do Estado de São Paulo (SEE-SP), 2009a. 
SEE/SP. Proposta Curricular do Estado de São Paulo para a disciplina de Sociologia. São Paulo: Secretaria da Educação do Estado de São Paulo (SEE-SP), 2009b.

SNYDERS, G. Escola, classe e luta de classes. Lisboa (Portugal): Moraes Editores, 1977.

TOMAZI, N. D. Sociologia para o ensino médio. São Paulo: Editora Saraiva, 2011

VIGOTSKI, L. S. A formação social da mente. $6^{\text {a }}$ Ed. São Paulo: Martins Fontes, 1998a.

VIGOTSKI, L. S. Pensamento e linguagem. 2a Ed. São Paulo: Martins Fontes, 1998b.

WEBER, M. "A ciência como vocação". In: WEBER, M. Ciência e política: duas vocações (pp. 15-52). São Paulo: Editora Cultrix, 1967.

Recebido em novembro-12

Aprovado em maio-13

Notas

\footnotetext{
${ }^{1}$ Professor do curso de Ciências Sociais da Universidade Federal de São Paulo (Unifesp/campus Guarulhos) e coordenador do Grupo de Estudos e Pesquisas Educação e Classes Sociais (Gepecso/Unifesp). Correio eletrônico: davisson.souza@unifesp.br.

2 Este artigo foi desenvolvido inicialmente como trabalho da disciplina "Pedagogia Histórico-Crítica", ministrada pela Profa. Mara Regina Martins Jacomeli e pelo Prof. Dermeval Saviani, e foi oferecida pelo Programa de Pós-Graduação em Educação da Unicamp no segundo semestre de 2010. Agradeço ao Prof. Dermeval Saviani e à Profa. Anita Handfas pela leitura atenta e sugestões feitas a versões provisórias do texto.

${ }^{3}$ Estas questões vêm sendo observadas ao longo de nossa experiência como docente da disciplina de Estágio Supervisionado em Ciências Sociais, a qual confirma diversos aspectos apresentados pela bibliografia que trata do ensino de Sociologia, tal como ficará mais claro ao longo do artigo.

${ }^{4}$ Por contemplar uma diversidade de autores da disciplina, aparentemente esse ecletismo não toma partido de nenhum deles; ou seja, apresenta-se como neutro do ponto de vista do marco teórico.

${ }^{5}$ Nosso intuito com essa problematização não é o de enfraquecer os argumentos favoráveis à presença da Sociologia na educação básica, supondo a impossibilidade epistemológica de seu tratamento na educação básica. Ao contrário, nossa intenção é contribuir para o debate sobre a transposição didática do conhecimento científico produzido no campo das Ciências Sociais para o conhecimento escolar trabalhado nas aulas de Sociologia.

${ }^{6}$ Sobre esta questão ver, por exemplo, Faria (1984).

${ }^{7}$ Embora esses documentos não tenham força de lei, pois como a própria denominação deixa explícita, tratam-se de "parâmetros" e "orientações", na prática se tornam "obrigatórios", pois são levados em conta nos mecanismos de avaliação e utilizados como referência na elaboração dos livros didáticos e na construção de critérios do MEC para indicação no PNLD.

8 Nosso objetivo é explicitar e problematizar aspectos muito gerais dos referenciais teóricos e epistemológicos das propostas curriculares e livros didáticos. Não se trata, portanto, de uma leitura minuciosa dos mesmos, o que exigiria um esforço de demonstração que ultrapassa os objetivos deste artigo. Também não se trata de uma crítica que visa desmerecer o trabalho de seus autores. Ao contrário, reconhecemos o papel que esses documentos e manuais tiveram para o retorno e a consolidação da Sociologia no Ensino Médio. Por isso, é necessário fazer a advertência de que apesar do tom polêmico presente na identificação de pontos comuns, existe grande diversidade teórica entre os autores e documentos analisados, bem como descontinuidades em relação aos elementos que destacamos.
} 
${ }^{9}$ Como afirmam os próprios Berger e Luckmann na Conclusão do livro: “(...) nossa concepção da sociologia do conhecimento implica uma particular concepção da sociologia em geral. Não implica que a sociologia não seja uma ciência, que seus métodos não devam ser empíricos ou que não pode ser 'livre de valores'. Implica que a sociologia toma seu lugar na companhia das ciências que tratam do homem enquanto homem" (1973, p. 247, os grifos e as aspas são dos autores).

${ }^{10}$ Além dessa crítica teórico-metodológica mais geral, consideramos, de qualquer forma, que os conceitos de "estranhamento" e "desnaturalização" não podem ser considerados parâmetros epistemológicos específicos da Sociologia. Se definirmos a ciência, ainda que de maneira preliminar, como um estudo sistemático da realidade, que busca compreender as relações objetivas (no mundo natural, físico e social) desnaturalizando as concepções míticas, religiosas e de senso comum, podemos chegar às seguintes conclusões: 1) Todo processo de desnaturalização exige uma postura de estranhamento do cientista, seja diante de uma nova realidade seja em relação ao acúmulo de conhecimento científico anterior em seu campo; 2) Assim, se o estranhamento e a desnaturalização constituem etapas inerentes ao processo de construção do conhecimento científico, são conceitos que abarcam a própria definição de ciência; 3) Portanto, não podem ser considerados conceitos matrizes específicos da Sociologia, mas da Ciência como um todo; 4) Nesse sentido, a especificidade da Sociologia estaria apenas na delimitação de seu campo de conhecimento que, como ciência histórica e social, busca a desnaturalização e o estranhamento da realidade social.

${ }^{11}$ Não é o foco deste trabalho entrar neste polêmico debate. Algumas ressalvas importantes em relação ao conceito de "objetividade" em Weber foram expostas por Cohn (1982), assim como algumas críticas pertinentes à noção de neutralidade axiológica foram sistematizadas por Löwy (1985). Cohn afirma que Weber admitia a dificuldade de ser "objetivo" nas Ciências Sociais, o que o levava a utilizar o conceito sempre entre aspas. Löwy argumenta que embora Weber tenha avançado em relação ao positivismo, sua concepção de objetividade e neutralidade pode ser considerada um resquício positivista do autor.

${ }^{12}$ Vale ressaltar que este material também se fundamenta na necessidade de articular "as três dimensões do ensino de Sociologia", ao afirmar que "não importa por onde começar, desde que conceitos, teorias e temas não fiquem dissociados".

13 Na tese III, explicita Marx: “A doutrina materialista segundo a qual os homens são produtos das circunstâncias e da educação e, portanto, segundo a qual os homens transformados são produtos de outras circunstâncias e de uma educação modificada, esquece que são precisamente os homens que transformam as circunstâncias e que o próprio educador deve ser educado” (MARX, 1996, p. 126).

${ }^{14}$ A nosso ver, duas das principais questões tratadas até aqui - a busca de neutralidade do conhecimento científico e o ecletismo acadêmico - estão intimamente relacionados, na medida em que a necessidade de abordar a diversidade teórica da disciplina é uma forma de sustentar a não pretensão de tomada de partido de qualquer corrente específica. Ou seja, tratar de "todos" seria uma forma de demonstrar a não preferência por "nenhum".

${ }^{15}$ Os livros de História não se colocam o objetivo de entrar na discussão acadêmica sobre as diferentes noções de fato, sujeito e tempo histórico, por exemplo, segundo a Escola dos Annales e seus principais representantes (Fernand Braudel, Jacques Le Goff, Lucien Febvre, Marc Bloch, entre outros) ou segundo a História Social britânica e seus teóricos mais relevantes (Christopher Hill, Edward Thompson, Eric Hobsbawn etc.). E além das diferentes abordagens sobre os eventos históricos, cabe registrar também que os manuais didáticos de História apresentam diversas formas de recorte do tempo histórico. É possível encontrar livros baseados tanto na abordagem cronológica clássica, em que a História Geral e do Brasil são tratadas separadamente e de forma linear, como a abordagem "integrada", em que estas passam a ser apresentadas de forma articulada, ou ainda a perspectiva "temática", em que diversos temas são tratados em uma perspectiva histórica comparada sem a necessidade de seguir uma linearidade no tempo, permitindo maior flexibilidade cronológica. Em suma, há materiais para todos os gostos e filiações teóricas, sem a necessidade de que cada um deles apresente a "diversidade" presente em seu campo científico.

${ }^{16}$ Para expor os fundamentos da PHC, baseamo-nos especialmente em três dos principais livros de Saviani (2008a, 2008b, 2009).

${ }^{17}$ Há outros autores que fazem críticas semelhantes às de Saviani às teorias mencionadas. Ver, por exemplo, Freitag (1978) e Snyders (1977). Porém, a originalidade de Saviani está em buscar uma síntese dialética entre essas teorias.

${ }^{18}$ Esta diferenciação é importante e pode ser sintetizada da seguinte forma: enquanto as teorias educacionais consideram a educação apenas sob o ponto de vista do conhecimento para esclarecer em que ela consiste, as teorias pedagógicas têm o objetivo de orientar a prática educativa, mostrando como ela deve ser realizada. 
${ }^{19}$ Esta noção se diferencia da concepção escolanovista segundo a qual a educação é o meio por excelência da transformação social. Para a PHC, a escola pode cumprir um papel de mediadora entre a teoria transformadora e a prática transformadora, já que esta última é exercida pelos enfrentamentos sociais, nos quais o partido revolucionário cumpre um papel histórico fundamental.

${ }^{20}$ Saviani diferencia produção de saber e elaboração de saber, e ressalta a importância e a centralidade da expressão escrita por conta da impossibilidade de se fazer ciência oral.

${ }^{21}$ É possível aqui uma analogia estabelecida com a crítica ao espontaneísmo feita por Lênin. Em Que fazer?, ao argumentar sobre a necessidade de desenvolver a "educação política da classe operária" como forma de superar a estratégia meramente sindical, Lênin afirma que "A consciência política de classe não pode ser levada ao operária senão do exterior, isto é, do exterior da luta econômica, do exterior da esfera das relações entre operários e patrões" (Lênin, 1978, p. 62).

${ }^{22}$ Apesar de Vigotsky ser a grande referência da concepção psicológica da qual parte a PHC, vale ressaltar que há outros importantes teóricos da Psicologia e da Pedagogia Revolucionária Russa, tais como Luria, Leontiev, Makarenko e Pistrak, nos quais Saviani se fundamenta para desenvolver sua teoria. Para um estudo sobre a unidade psico-pedagógica entre a PHC e a Psicologia Histórico-Cultural, ver Scalcon (2002).

${ }^{23}$ Nesse sentido, $O$ Capital, obra máxima do autor, pode ser compreendido como um todo articulado na forma de sistema de conceitos (cuja célula analítica é a mercadoria e o fundamento mais geral é a teoria do valor) que deve sempre ser submetido à tensão entre diacronia e sincronia, e entre estrutura e conjuntura.

${ }^{24}$ Assim, se os cinco passos da Pedagogia tradicional são a) Preparação; b) Apresentação; c) Assimilação; d) Generalização; e e) Aplicação, os cinco passos das Pedagogias inovadoras são a) Atividade; b) Problema; c) Coleta de dados; d) Hipótese; e e) Experimentação.

${ }^{25}$ Esta é uma comparação de cunho didático, pois estes momentos podem ser (ou não) correspondentes. Não se trata, portanto, de um arranjo que concilia essas duas posições, por exclusão ou por ecletismo, mas sim de uma incorporação por superação.

${ }^{26}$ É aí que o sujeito se torna "livre", pois passa a dominar os automatismos. Para Saviani, o aprendiz nunca é livre, pois no momento em que se torna livre deixa de ser aprendiz. Segundo o autor, quando se automatiza (in-corpora) as operações, pode-se operá-las livremente. Esta proposição também está apoiada em Gramsci (1968).

${ }^{27}$ Ou seja, o ponto de partida do conhecimento pedagógico é o aluno inserido na prática social; e não os alunos segundo suas experiências prévias individuais.

${ }^{28}$ Embora este objetivo mais geral seja correspondente, é necessário levar em conta que, como disciplina científica, a Sociologia tem outros objetivos, entre os quais podemos destacar a realização da pesquisa sociológica, o debate sobre o "sistema de conceitos científicos" próprio de seu campo, e a discussão teóricometodológica entre as correntes teóricas e os autores. A não consideração dessa diferença tem levado muitos autores e professores à mera transposição mecânica do tratamento científico da disciplina na abordagem da matéria escolar, sem a devida tradução didática dos seus conteúdos e adaptação epistemológica dos seus objetivos.

${ }^{29}$ Também observamos essa questão em nossa experiência como professora de Estágio Supervisionado em Ciências Sociais, especialmente no relato dos alunos durante a visita às escolas.

${ }^{30}$ Handfas e Teixeira (2007, p. 140) chamam atenção para esta questão e, utilizando o repertório conceitual da PHC, ressaltam a importância de se distinguir "o trabalho educativo voltado para a experiência imediata ou empírico do indivíduo - que corresponderia ao conhecimento tácito, e o trabalho educativo voltado para a produção de indivíduos inseridos numa prática social que forma o acervo cultural e científico produzido e acumulado historicamente pela humanidade - que corresponderia ao conhecimento escolar". Para uma crítica às pedagogias que partem da noção de conhecimento tácito, ver Duarte (2003).

${ }^{31}$ Como se sabe, na maioria dos estados, a disciplina de Sociologia conta com duas e em algumas séries, com apenas uma hora-aula.

${ }^{32} \mathrm{O}$ que se observa freqüentemente nos manuais é que, embora os conceitos e teorias sejam tratados de modo relativamente plural, a abordagem de determinados temas ganha contornos teórico-conceituais mais específicos nos capítulos seguintes. No item I fizemos referência às escolhas feitas pelos PCN no tratamento de alguns temas. Os exemplos poderiam ser multiplicados por meio de uma análise mais aprofundada do conteúdo dos livros didáticos analisados, e especialmente de seu currículo oculto (ou seja, os temas e conceitos que não tratados). 